\title{
THE EFFECTS OF CYCLIC TENSILE STRAIN ON THE ORGANISATION AND EXPRESSION OF CYTOSKELETAL ELEMENTS IN BOVINE INTERVERTEBRAL DISC CELLS: AN IN VITRO STUDY
}

\author{
Siyuan $\mathrm{Li}^{1}$, Xiaoli Jia ${ }^{2}$, Victor C. Duance ${ }^{1,3 *}$ and Emma J. Blain ${ }^{1,3}$ \\ ${ }^{1}$ Arthritis Research UK Biomechanics and Bioengineering Centre, School of Biosciences, Cardiff University, \\ Cardiff, UK \\ ${ }^{2}$ The Department of Infectious Disease, the Second Hospital of Xi'an \\ Jiaotong University, Xi'an, China \\ ${ }^{3}$ Division of Pathophysiology and Repair, School of Biosciences, Cardiff University, Cardiff, UK
}

\begin{abstract}
It is still relatively unclear how intervertebral disc (IVD) cells sense a mechanical stimulus and convert this signal into a biochemical response. Previous studies demonstrated that the cytoskeletal elements are mechano-responsive in many cell types and may contribute to mechano-signalling pathways. The objective of this study was to determine the response of cells from the outer annulus fibrosus (OAF) to physiological levels of cyclic tensile strain; further, cells from the nucleus pulposus (NP) were also subjected to an identical loading regime to compare biological responses across the IVD populations. We determined whether the organisation and expression of the major cytoskeletal elements and their associated accessory proteins are responsive to mechanical stimulation in these cells, and whether these changes correlated with either a catabolic or anabolic phenotype. OAF and NP cells from immature bovine IVD were seeded onto Flexcell ${ }^{\circledR}$ type I collagen coated plates. Cells were subjected to cyclic tensile strain $(10 \%, 1 \mathrm{~Hz})$ for 60 minutes. Post-loading, cells were processed for immunofluorescence microscopy, RNA extracted for quantitative PCR and protein extracted for Western blotting analysis. F-actin reorganisation was evident in OAF and NP cells subjected to tensile strain; strain induced $\beta$-actin at the transcriptional and translational level in OAF cells. $\beta$-tubulin mRNA and protein synthesis increased in strained OAF cells, but vimentin expression was significantly inhibited. Cytoskeletal element organisation and expression were less responsive to strain in NP cells. Tensile strain increased type I collagen and differentially regulated extracellular matrix (ECM)-degrading enzymes' mRNA levels in OAF cells. Strain induced type II collagen transcription in NP cells, but had no effect on the transcription of any other genes analysed. Tensile strain induces different mechano-responses in the organisation and/or expression of cytoskeletal elements and on markers of IVD metabolism. Differential mechano-regulation of anabolic and catabolic ECM components in the OAF and NP populations reflects their respective mechanical environments in situ.
\end{abstract}

Keywords: Intervertebral disc, mechanotransduction, cytoskeleton, actin filaments, microtubules, intermediate filaments, cyclic tensile strain, nucleus pulposus, outer annulus fibrosus, extracellular matrix.
*Address for correspondence:

Victor C. Duance

Arthritis Research UK Biomechanics and Bioengineering Centre

School of Biosciences

Cardiff University, Museum Avenue

Cardiff, CF10 3AX, UK

Telephone Number: $+44(0) 2920874111$

FAX Number: +44(0)2920874594

E-mail: duance@cf.ac.uk

\section{Introduction}

The spine is a complex structure comprising vertebrae, muscles and ligaments that combine to provide strength and flexibility during movement. To enable extension, flexion, lateral bending and rotation, each vertebral body is interposed with a soft deformable tissue, namely the intervertebral disc (IVD) (Mirza and White, 1995). The IVD can be divided into three anatomically distinct areas: the outer region that is the annulus fibrosus (AF) which can be further categorised into inner (IAF) and outer (OAF) annulus fibrosus, the central nucleus pulposus (NP), and the cartilaginous endplates (CEP) on the superior and inferior surface. The NP functions to resist compressive loads, whilst the $\mathrm{AF}$, and in particular the $\mathrm{OAF}$, primarily withstands tensional forces applied to the spine (Klein et al., 1983).

Under compression, the NP deforms and equilibrates the compressive forces both horizontally and vertically across the NP; these forces are resisted by the surrounding $\mathrm{AF}$ and CEP. Therefore a component of the compressive load is absorbed by the NP and the remaining load is converted into a tensional force which is absorbed by the deformation of the AF, especially the OAF. These forces remain in the NP and dissipate into adjacent IVDs through the stiff vertebral body. Previous studies have shown that the strain resisted by the OAF is between 1 and 13\% (Broberg, 1983; Klein et al., 1983; Ebara et al., 1996; Rannou et al., 2003).

Key extracellular matrix (ECM) components including collagen, aggrecan, ECM-degrading enzymes, i.e., matrix metalloproteinases (MMPs), and aggrecanases (ADAMTSs), and the tissue inhibitors of MMPs (TIMPs) are all subject to differential regulation when IVD tissue is subjected to mechanical stimulation (Matsumoto et al., 1999; Rannou et al., 2003; Benallaoua et al., 2006). It is still relatively unclear how cells of the IVD sense 
a mechanical stimulus and convert this signal into a biochemical response. However, previous studies have intimated that the cytoskeletal elements, i.e., actin, tubulin and vimentin, are mechano-responsive in many cell types and may contribute to the mechano-signalling pathways (Samuel et al., 1986; Takahashi et al., 1998; Jortikka et al., 2000; Hayes et al., 2001; Kaverina et al., 2002; Chen et al., 2004; Setton and Chen, 2004; Yu et al., 2005; Campbell et al., 2007).

Our previous study has shown that there are significant differences in the organisation and expression of cytoskeletal elements between NP and OAF cells in situ (Li et al., 2008), which may reflect the distinct mechanical characteristics of the two cell populations in vivo. If cytoskeletal elements play a pivotal role in mechanotransduction in IVD cells, there may be a differential response to the same mechanical stimulus i.e. tensional strain between NP and OAF cells due to their distinct mechanical characteristics and cell phenotypes. However, to date there have been few studies investigating these phenomena.

The two IVD cell populations, namely the NP and OAF, were subjected to cyclic tensile strain, considered to be a physiological mechanical stimulus for OAF cells but an abnormal stimulus for NP cells in vivo. The aim of this study was to determine whether the three major cytoskeletal elements and their associated accessory proteins respond to mechanical stimulation in the IVD, and whether there is a differential response to cyclic tensile strain depending on the cell type loaded.

\section{Materials and Methods}

All chemicals were of analytical grade or above and from Sigma-Aldrich (Poole, UK) unless otherwise stated. Culture medium consisted of Dulbeccos Modified Eagle's Medium/Hams F12 (DMEM/F12 (1:1); Invitrogen, Paisley, UK) supplemented with $100 \mathrm{U} / \mathrm{mL}$ penicillin and 100 $\mu \mathrm{g} / \mathrm{mL}$ streptomycin (Invitrogen), $1 \%$ (v/v) fungizone (Invitrogen) and $1 \mathrm{x}$ insulin-transferrin-sodium selenite (1x ITS) unless indicated otherwise.

\section{Cell isolation and culture}

Bovine tails (approximately 7 day old steers) were obtained from the abattoir within $6 \mathrm{~h}$ of slaughter. NP and OAF from the proximal coccygeal discs (CC1-CC5) were dissected under an anatomical microscope and cells isolated as described previously (Li et al., 2008). Cell number and viability were determined using the Trypan blue assay. Cells were cultured in DMEM/F12 (1:1) containing 10 $\%$ (v/v) FBS plus $100 \mu \mathrm{g} / \mathrm{mL}$ penicillin-streptomycin and $1 \%$ fungizone at $37{ }^{\circ} \mathrm{C}$ in a humidified atmosphere of 5 $\% \mathrm{CO}_{2}$. After stabilisation for $4 \mathrm{~d}$, medium was removed and replenished every $2 \mathrm{~d}$ thereafter until cells reached confluence.

\section{Application of cyclic tensile strain}

NP and OAF cells were passaged using $0.25 \%(\mathrm{w} / \mathrm{v})$ trypsin-EDTA solution (Invitrogen, Paisley, UK) and reseeded $\left(0.5 \times 10^{6} / \mathrm{cm}^{2}\right)$ as a monolayer culture in 6-well flexible-bottomed type I collagen coated culture plates (Flex I ${ }^{\mathrm{TM}}$ culture plates; Flexcell International, Hillsborough, NC, USA). Cells were stabilised in culture medium for $24 \mathrm{~h}$ prior to application of cyclic strain. CTS of $10 \%$ elongation $(1 \mathrm{~Hz}$ ) (Rannou et al., 2003) was applied to cells for 60 min using the Flexcell FX-3000 system (Flexcell International); $10 \%$ elongation is considered to be a physiological mechanical stimulus for OAF cells in vivo. NP cells are not normally exposed to tensile forces in vivo and hence, the comparison with how NP cells respond to a non-physiological mechanical stimulus was performed. As a control, cells were cultured equivalently in all steps but were devoid of CTS. After application of strain, cells were lysed immediately in Trizol ${ }^{\mathrm{TM}}$ reagent (Invitrogen) for RNA extraction, or were lysed in $1 \%(\mathrm{v} / \mathrm{v})$ Triton X-100 plus protease inhibitors (Cocktail I) for protein analysis, or were fixed with $4 \%(\mathrm{w} / \mathrm{v})$ paraformaldehyde in PBS at room temperature for immunolocalisation studies.

\section{Analysis of cell viability: LDH assay}

To investigate whether tensile strain induced cell death, cell viability was determined using the Lactate Dehydrogenase (LDH) assay (Promega, Southampton, UK). Total LDH (reflecting cell number) and LDH levels in the culture media (reflecting cell death) were determined using the LDH assay according to the manufacturer's protocol. Cell viability was calculated according to the formula below:

$$
\text { Analysis of cell viability }=\left(1-\frac{\mathrm{LDH} \text { levels in culture medium }}{\text { Total LDH levels }}\right) \times 100 \%
$$

\section{Analysis of cytoskeletal element organisation using scanning laser confocal microscopy}

Cytoskeletal element organisation in OAF and NP cells subjected to tensile strain was investigated using immunofluorescence in conjunction with scanning laser confocal microscopy as previously described (Li et al., 2008) with minor modifications. Four regions of the membrane $(0.5 \times 2 \mathrm{~cm})$ were excised from the flexible-bottomed Flex I culture plates using a scalpel. Representative samples were excised from each quadrant of the membrane for analysis. After fixation in $4 \%$ $(\mathrm{w} / \mathrm{v})$ paraformaldehyde, cells were permeabilised in $0.5 \%(\mathrm{v} / \mathrm{v})$ Triton X-100 and blocked with $10 \%(\mathrm{v} / \mathrm{v})$ normal goat serum prior to overnight incubation with mouse anti-vimentin V9 antibody (1:100), or mouse anti-tubulin E7 antibody (1:100, Developmental Studies Hybridoma Bank, Iowa City, IA, USA), respectively. Sections were washed extensively and incubated in goat anti-mouse Alexa633 ${ }^{\mathrm{TM}}$-conjugated secondary antibody (1:300) for $1 \mathrm{~h}$. Actin filaments were stained with Alexa 488 conjugated phalloidin (1:40 dilution; Invitrogen). Sections were mounted in Vectorshield ${ }^{\mathrm{TM}}$ containing DAPI (Vectashield, Vectorlabs, Burlingame, CA, USA). Sections were visualised using a Leica DM6000B upright digital microscope (Leica, Wetzlar, Germany) set up for dual-channel fluorescence recordings. Representative cells were scanned using a $63 x$ oil immersion objective with appropriate excitation and emission settings for fluoroscein isothiocyanate and DAPI. Negative controls, omitting the primary antibody, conducted in parallel were devoid of fluorescent signal (data not shown). 
Table 1. Primer sequences of genes of interest.

\begin{tabular}{c|c|c|c|c}
\hline Gene & Primer sequence & Tm ('C) $^{\circ}$ & Product size (bp) & Accession No. \\
\hline Type I collagen & $\begin{array}{c}\text { Forward 5'-ACATGCCGAGACTTGAGACTCA-3' } \\
\text { Reverse: 5'-GCATCCATAGTACATCCTTGGTTAGG-3' }\end{array}$ & 61 & 86 & NM_174520 \\
\hline MMP-1 & $\begin{array}{c}\text { Forward 5'-CAAATGCTGGAGGTATGATGA-3' } \\
\text { Reverse: 5'-AATTCCGGGAAAGTCTTCTG-3' }\end{array}$ & 60 & 82 & NM_174112 \\
\hline MMP-2 & $\begin{array}{c}\text { Forward 5'-TCTGCCCCCATGAAGCCCTGTT-3' } \\
\text { Reverse 5'-GCCCCACTTGCGGTCATCATCGTA-3' }\end{array}$ & 65 & 347 & NM_174745 \\
\hline MMP-3 & $\begin{array}{c}\text { Forward: 5'-TGGAGATGCTCACTTTGATGATG-3' } \\
\text { Reverse: 5'-GAGACCCGTACAGGAACTGAATG-3' }\end{array}$ & 60 & 221 & XM_586521 \\
\hline TIMP-1 & $\begin{array}{c}\text { Forward: 5'-CTGCGGATACTTCCACAGGT-3' } \\
\text { Reverse: 5'-ATGGATGAGCAGGGAAACAC-3' }\end{array}$ & 60 & 75 & NM_174471 \\
\hline TIMP-2 & $\begin{array}{c}\text { Forward: 5'-ATAGTGATCAGGGCCAAAGCAGTC-3' } \\
\text { Reverse: 5'-TGTCCCAGGGCACGATGAAGTC-3' }\end{array}$ & 63 & 27472 \\
\hline Vinculin & $\begin{array}{c}\text { Forward: 5'-GCACGATTGAGAGCATTCTG-3' } \\
\text { Reverse: 5'-GCACGATTGAGAGCATTCTG-3' }\end{array}$ & 57 & NM_001078093 \\
\hline Thymosin $\beta_{4}$ & $\begin{array}{r}\text { Forward: 5'-GGTTTTAAAACTTTTTATTTG-3' } \\
\text { Reverse: 5'-TGGGACGACAGTGAAA-3' }\end{array}$ & 60 & 156 & BC133478 \\
\hline
\end{tabular}

Analysis of cytoskeletal element gene expression using quantitative PCR

Total RNA was extracted, and cDNA was synthesised as previously described (Li et al., 2008). Briefly, Trizol ${ }^{\mathrm{TM}}$ reagent (Invitrogen) was added directly to the cells and incubated at room temperature for $10 \mathrm{~min}$. Following chloroform extraction, samples were precipitated with $70 \%$ ethanol, and the RNA purified using Qiagen RNeasy mini kits according to the manufacturer's protocols (Qiagen, Hilden, Germany). First strand cDNA was synthesised by reverse transcription $(2 \mu \mathrm{L}$ RNA solution $/ 20 \mu \mathrm{L}$ reaction volume) using Superscript ${ }^{\mathrm{TM}}$ II reverse transcriptase (Invitrogen) according to the manufacturer's protocols. Cytoskeletal element gene expression in OAF and NP cells was investigated using quantitative PCR using the $\mathrm{Mx} 3000 \mathrm{P}^{\circledR} \mathrm{qPCR}$ system as described previously using primers designed to the open reading frame of specific target genes (Blain et al., 2006; Campbell et al., 2007; Li et al., 2008) (for unpublished primers refer to Table 1), in conjunction with Sybr Green ${ }^{\mathrm{TM}}$ detection. GAPDH was used as an internal reference of housekeeping gene transcription for normalisation between different cDNA samples as described previously (Blain et al., 2006). Data are presented as fold-change in gene expression after normalisation to GAPDH and the unloaded control cDNA samples.

\section{Analysis of cytoskeletal element protein expression using Western blotting}

Cytoskeletal element protein levels in OAF and NP cells subjected to cyclic tensile strain were investigated using Western blotting as described previously with minor modifications (Blain et al., 2006; Li et al., 2008). Briefly, cellular protein was extracted by adding $1 \mathrm{~mL}$ of $1 \%(\mathrm{v} / \mathrm{v})$ Triton X-100 solution plus proteinase inhibitors (cocktail I). Cell lysates were added to $2 \mathrm{x}$ sample buffer $(0.06 \mathrm{M}$ Tris $\mathrm{pH} 6.8,2 \%(\mathrm{w} / \mathrm{v})$ SDS, $10 \%(\mathrm{v} / \mathrm{v})$ glycerol, $0.2 \%$ (w/v) bromophenol blue) and denatured for $30 \mathrm{~min}$ at 60 ${ }^{\circ} \mathrm{C}$ with reduction using $2.5 \%$ (v/v) $\beta$-mercaptoethanol. A $10 \%$ polyacrylamide gel was used to resolve the samples, which were loaded according to equivalent cell number as determined using the LDH assay. Proteins were transferred to PVDF membrane (Millipore, Watford, UK) at 100 $\mathrm{V}$ (60 min) followed by membrane blocking with $3 \%$ (w/v) skimmed milk. Immunoblotting of membranes was performed overnight with primary antibodies to mouse anti-actin (1:1000, Abcam), mouse anti-vimentin (1:400) or mouse anti-tubulin (1:500, Developmental Studies Hybridoma Bank) respectively. Membranes were washed extensively prior to incubation with HRP conjugated sheep anti-mouse secondary antibody (1:10000) for $60 \mathrm{~min}$. HRP signal was detected using ECL $\AA$ reagents (GE Healthcare, Little Chalfont, UK). Western blots were scanned and differences in the signal intensity of the digitised bands were assessed using NIH (Bethesda, MD, USA) Image software. Cells not subjected to tensile strain but cultured under the same conditions were used as controls for the different time points. To remove error induced by differences in film exposure, a control sample was used as a standard for normalisation purposes.

\section{Statistical analysis}

Data are presented as mean \pm S.E.M with tissue derived from between 4 and 6 individual animals; independent experiments were performed twice. Data was tested for normality (Anderson-Darling test) and equal distribution. A Students $t$-test was performed for direct comparisons; for multiple comparisons a two-way ANOVA followed by the Bonferroni post-hoc test was performed. Differences were considered statistically significant at $p<0.05$ (SPSS 12.0 software; SPSS, Chicago, IL, USA).

\section{Results}

Cyclic tensile strain did not influence cell viability To determine whether tensile strain induced cell death, cell viability was investigated at $0,3,8$ and $24 \mathrm{~h}$ after the application of strain ( $10 \%$ elongation, $1 \mathrm{~Hz}, 60 \mathrm{~min})$. Cell viability was not significantly affected by tensile strain at 
a
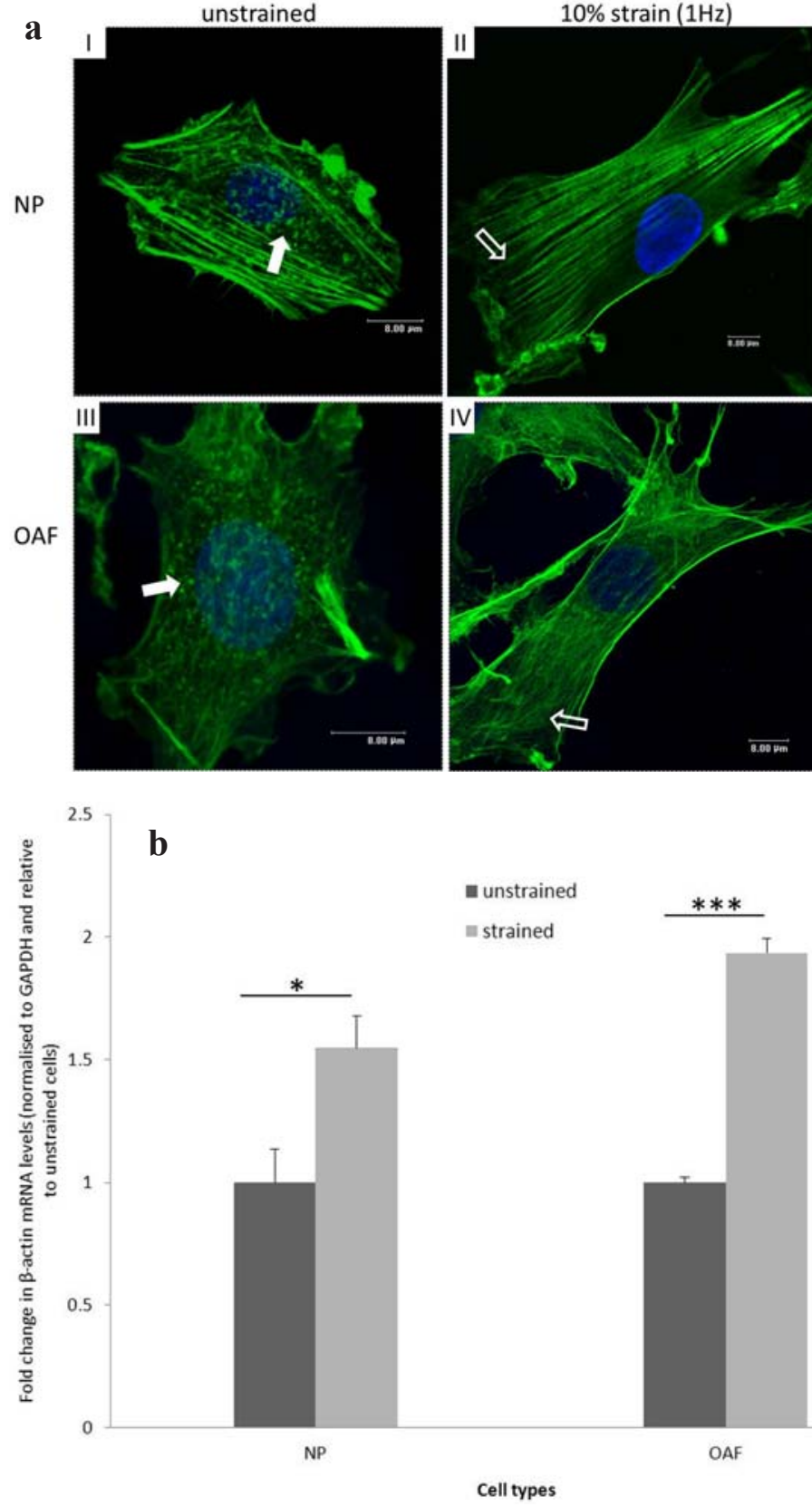

c

\begin{tabular}{|c|c|c|c|c|c|}
\hline after strain & 0 & 3 & 8 & 24 & (hours) \\
\hline strained & $\longrightarrow$ & 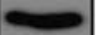 & $\Longrightarrow$ & - & $\beta$-actin \\
\hline unstrained & $\Longrightarrow$ & $=$ & $=$ & $\rightarrow$ & $\beta$-actin \\
\hline
\end{tabular}

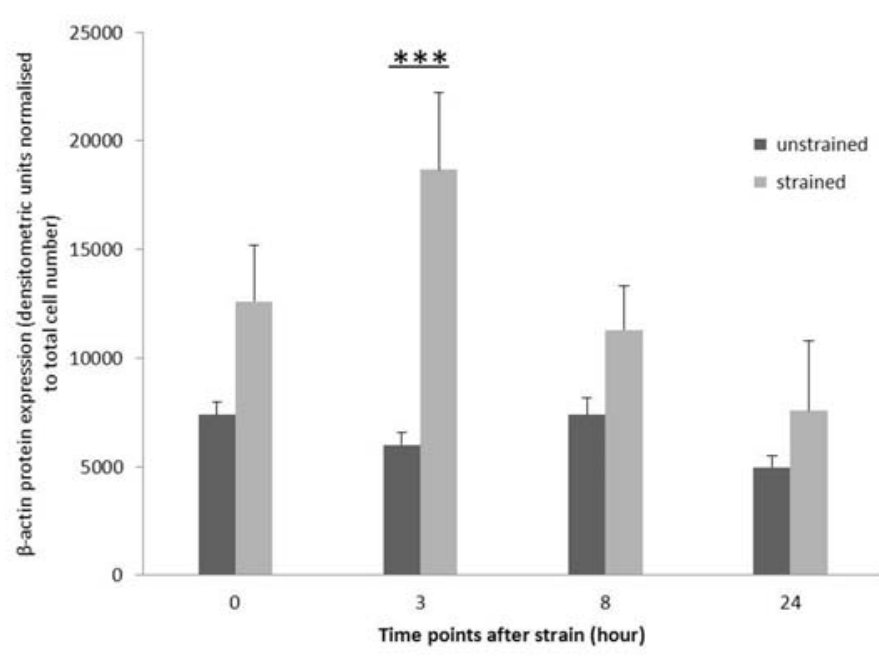

Fig. 1. The effect of tensile strain on the actin cytoskeleton of intervertebral disc cells cultured on type I collagen. (a) F-actin organisation in nucleus pulposus (NP) and outer annulus fibrosus (OAF) cells before and after $10 \%$ strain $(60 \mathrm{~min})$. Cells were visualized using Alexa-488 $8^{\mathrm{TM}}$-phalloidin (counterstained with 4',6-diamidino-2-phenylindole) in conjunction with confocal microscopy [scale bar $=8 \mu \mathrm{m}]$. Punctate F-actin labelling in NP and OAF cells was lost upon tensile strain, becoming replaced with extensive F-actin stress fibres. (b) The effect of tensile strain on $\beta$-actin mRNA expression assessed using quantitative PCR. Data are presented as mean fold change \pm S.E.M. after normalisation to the housekeeping gene GAPDH and relative to unstrained "control" cells $(n=5)$. Strain induced $\beta$-actin transcription in NP and OAF cells. (c) The effect of tensile strain on $\beta$-actin protein expression by OAF cells subjected to cyclic tensile strain for 60 min followed by culture for a further $0,3,8$ or $24 \mathrm{~h}$; Western blots were loaded on an equivalent number of cells and densitometric analyses performed. Unstrained cells were used as controls for the different time points. Data are presented as mean \pm S.E.M. $(\mathrm{n}=5) .{ }^{* *}: p \leq 0.001,{ }^{*}: p \leq 0.05$ when compared with control samples. 
a

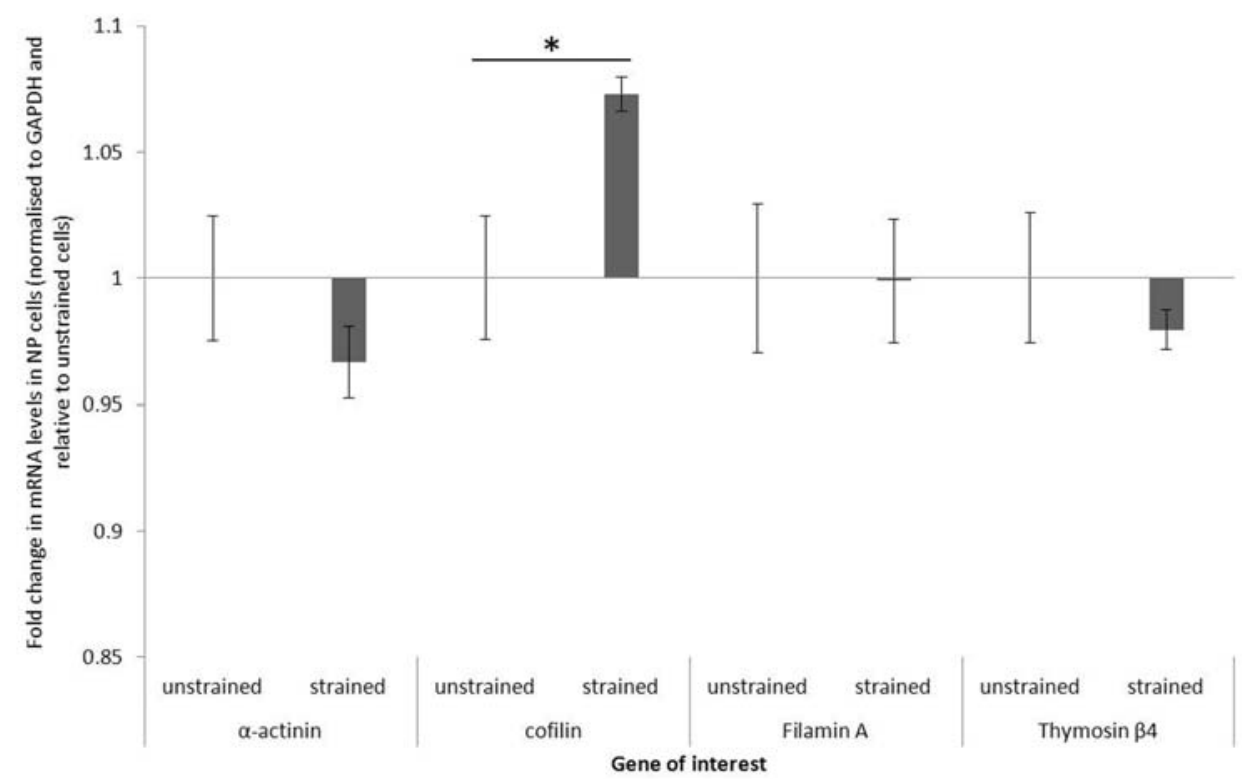

b

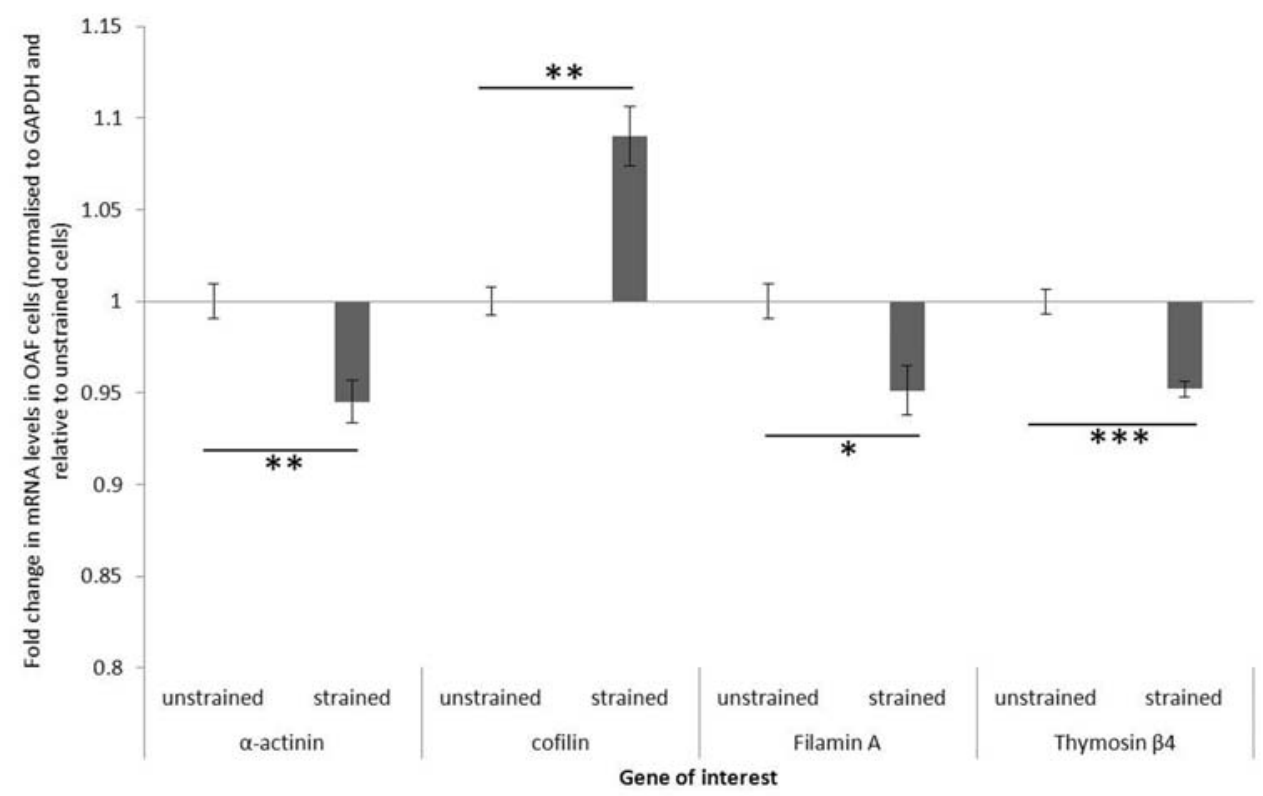

Fig. 2. Actin-binding protein gene expression in bovine (a) NP and (b) OAF cells subjected to tensile strain (10 $\%$ elongation, $1 \mathrm{~Hz}, 60 \mathrm{~min}$ ); unstrained cells were used as a control. Target gene mRNA levels were determined using real-time PCR and data normalised to the house-keeping gene GAPDH and relative to the control cells. Data are shown as mean \pm S.E.M. $(n=5)$. ${ }^{* *}: p \leq 0.001, * *: p \leq 0.01,{ }^{*}: p<0.05$ when compared with control group.

any of the time points analysed when compared with the control unstrained cells (data not shown: NP cells $p=0.943$ and OAF cells $p=0.358$ ).

\section{Differential regulation of F-actin in NP and OAF cells in response to tensile strain}

Strain induced re-organisation of F-actin in NP and OAF cells

F-actin filaments displayed a flattened morphology when cultured as a monolayer on type I collagen with randomly protruding cell processes in both NP and OAF cells. F-actin filaments were predominately localised beneath the cell membrane; F-actin was punctate in NP cells (Fig. 1a-I: white arrow), with evidence of a more fibrous network in the OAF cells (Fig. 1a-III). After the application of a 10 $\%$ strain $(1 \mathrm{~Hz}, 60 \mathrm{~min})$, the cells became elongated. The punctate distribution of F-actin was lost, and was replaced by a large number of F-actin stress fibres (Fig. 1a-II \& IV: white hollow arrow); these were observed throughout the cytoplasm and extended into the cellular protrusions of both cell populations.

Strain induced $\beta$-actin transcription in NP and OAF cells To determine whether the effect of tensile strain on F-actin organisation was purely organisational or due to altered expression, $\beta$-actin mRNA levels were quantified (Fig. 1b). Tensile strain induced $\beta$-actin transcription in NP (1.5-fold; $p<0.05$ ) and OAF cells (2-fold, $p<0.001$ ). 


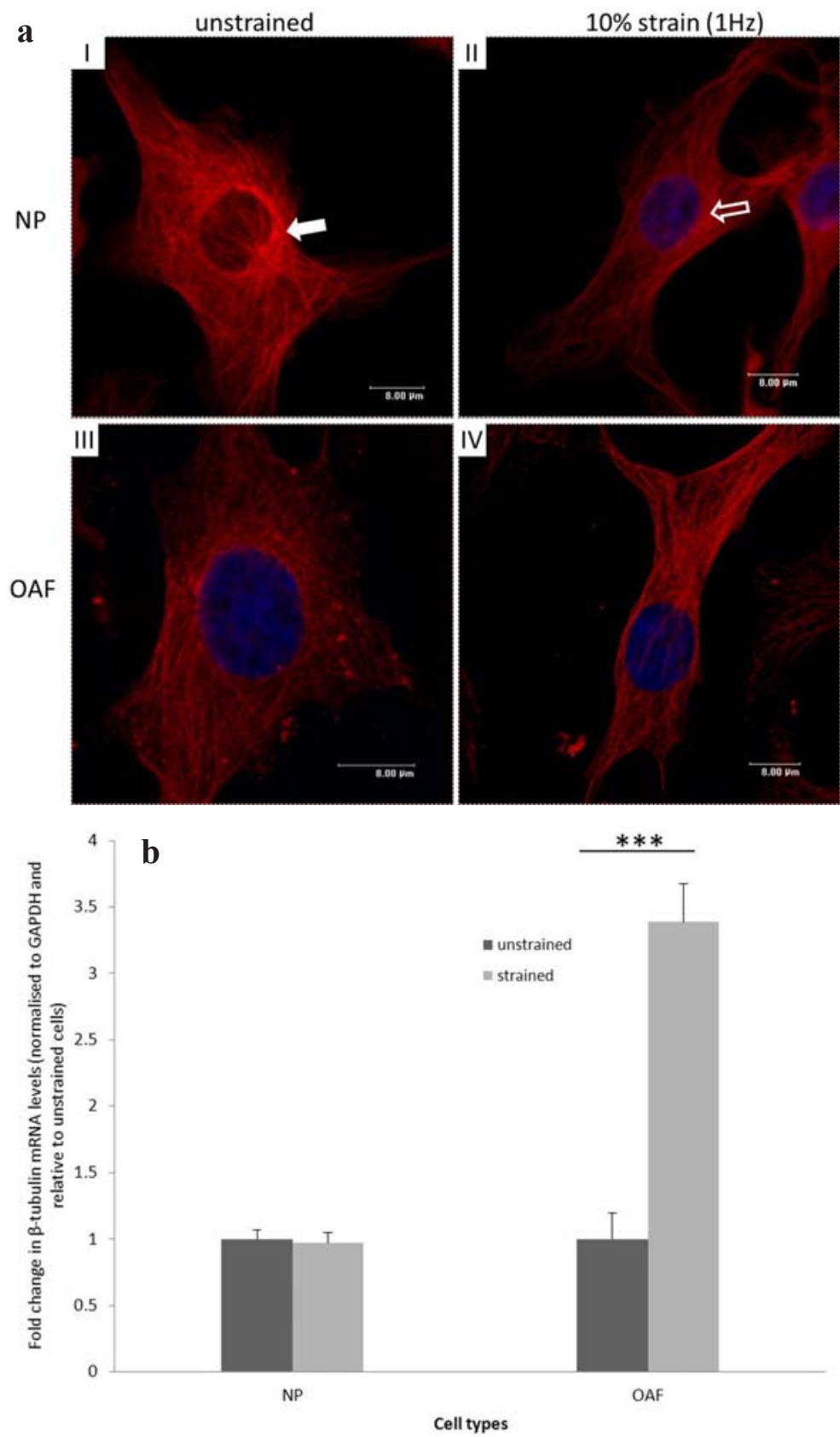

c
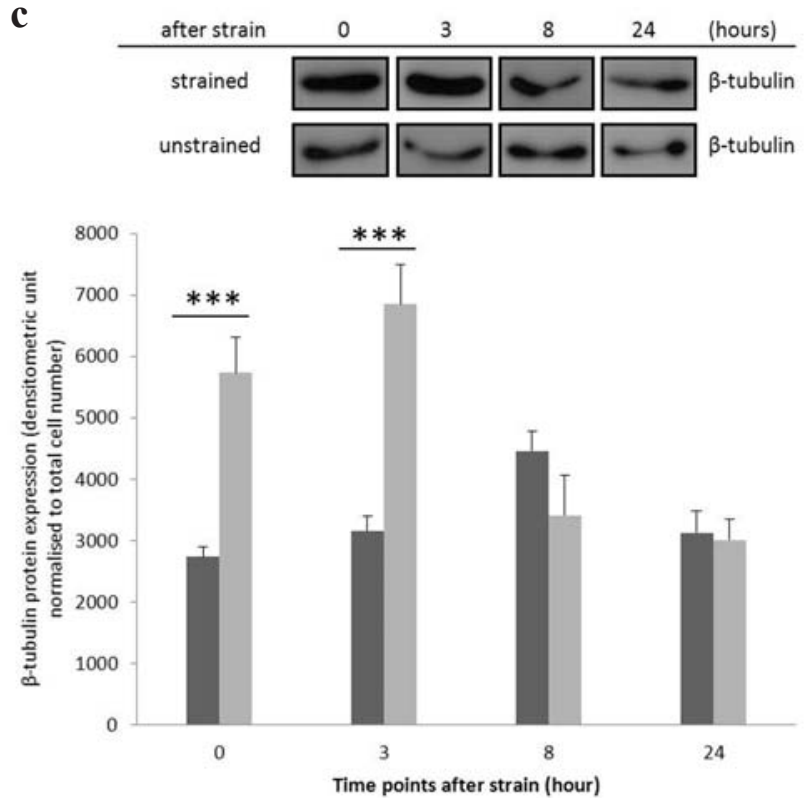

Fig. 3. The effect of tensile strain on the $\beta$-tubulin cytoskeleton of intervertebral disc cells cultured on type I collagen. (a) $\beta$-tubulin organisation in NP and OAF cells before and after $10 \%$ strain (60 min). Cells were visualised using mouse anti-tubulin primary antibody E7 and Alexa-633 $3^{\mathrm{TM}}$ conjugated anti-mouse IgG (counterstained with 4',6-diamidino-2-phenylindole) in conjunction with confocal microscopy [scale bar $=8 \mu \mathrm{m}]$. $\beta$-tubulin was mainly distributed throughout the cytoplasm, with evidence of peri-nuclear staining in unstrained NP cells (arrow, Fig.4a-I). Tensile strain decreased peri-nuclear localisation of $\beta$-tubulin in NP cells (arrow, Fig.4a-II). (b) The effect of tensile strain on $\beta$-tubulin mRNA expression assessed using quantitative PCR. Data are presented as mean fold change \pm S.E.M after normalisation to the housekeeping gene GAPDH and relative to unstrained "control" cells. $(n=5)$. Strain induced $\beta$-tubulin transcription in OAF cells. (c) The effect of tensile strain on $\beta$-tubulin protein expression by OAF cells subjected to cyclic tensile strain for $60 \mathrm{~min}$ followed by culture for a further $0,3,8$ or $24 \mathrm{~h}$; Western blots were loaded on an equivalent number of cells and densitometric analyses performed. Unstrained cells were used as controls for the different time points. Data are presented as mean \pm S.E.M. $(n=5) .{ }^{* * *}: p \leq 0.001$, when compared with control samples. 
a
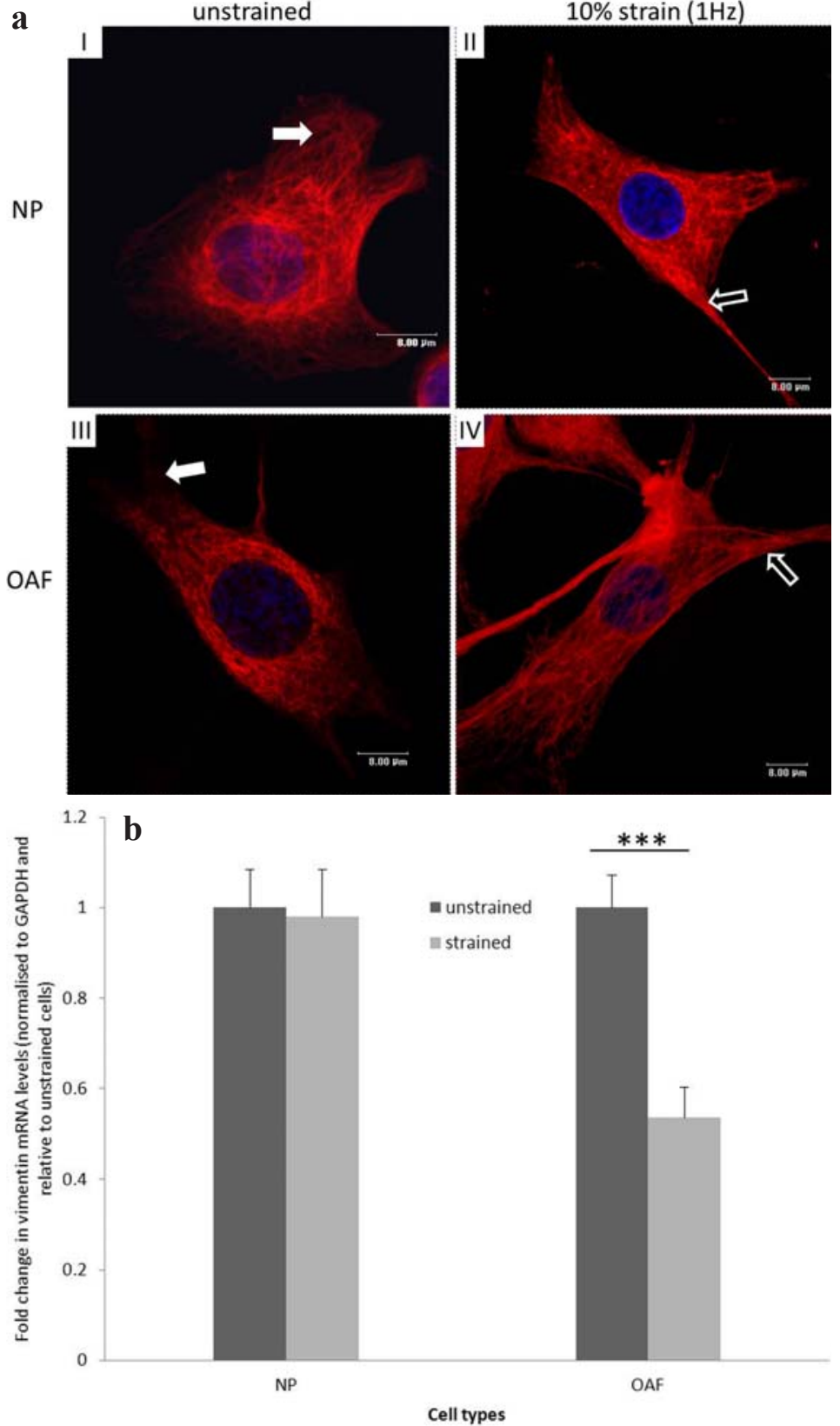

c
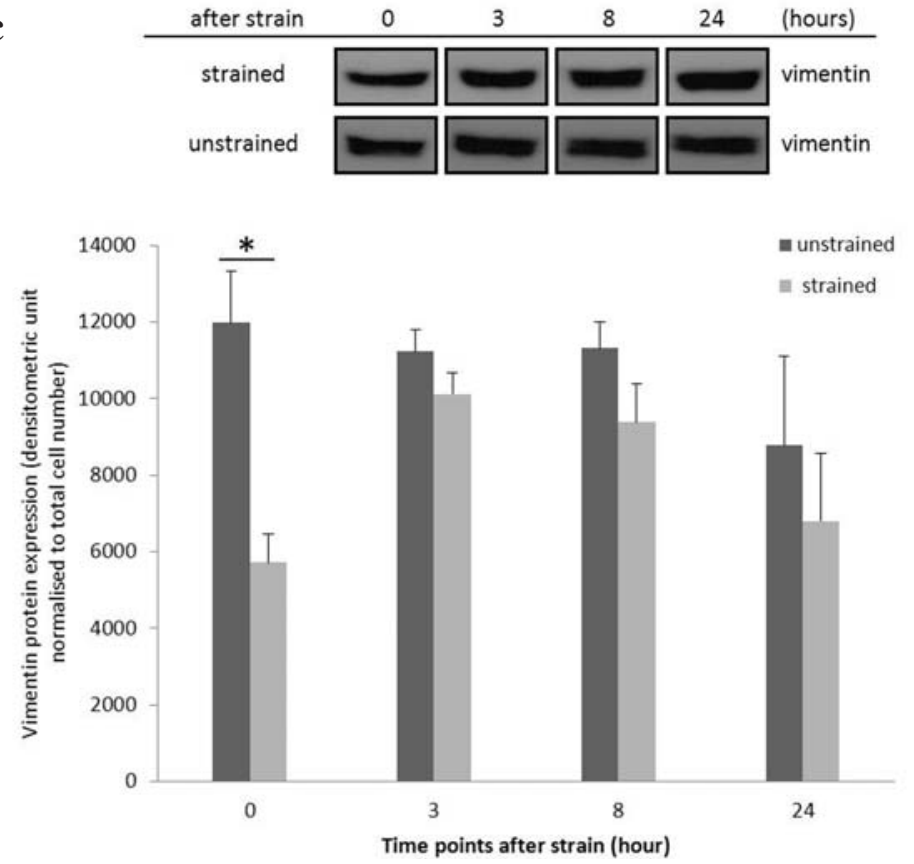

Fig. 4. The effect of tensile strain on the vimentin cytoskeleton of intervertebral disc cells cultured on type I collagen. (a) vimentin organisation in NP and OAF cells before and after $10 \%$ strain $(60 \mathrm{~min})$. Cells were visualised using mouse anti-vimentin primary antibody V9 and Alexa-633 $3^{\mathrm{TM}}$ conjugated anti-mouse $\operatorname{IgG}$ (counterstained with 4',6-diamidino-2-phenylindole) in conjunction with confocal microscopy [scale bar $=8 \mu \mathrm{m}]$. The extensive cytoplasmic distribution of vimentin was not affected by strain. (b) The effect of tensile strain on vimentin mRNA expression assessed using quantitative PCR. Data are presented as mean fold change \pm S.E.M after normalisation to the housekeeping gene GAPDH and relative to unstrained "control" cells. $(n=5)$. Strain transiently inhibited vimentin transcription in OAF cells. (c) The effect of tensile strain on vimentin protein expression by OAF cells subjected to cyclic tensile strain for $60 \mathrm{~min}$ followed by culture for a further $0,3,8$ or 24 $\mathrm{h}$; Western blots were loaded on an equivalent number of cells and densitometric analyses performed. Unstrained cells were used as controls for the different time points. Data are presented as mean \pm S.E.M. $(n=5) .{ }^{*}: p$ $\leq 0.05, * * *: p \leq 0.001$, when compared with control samples. 


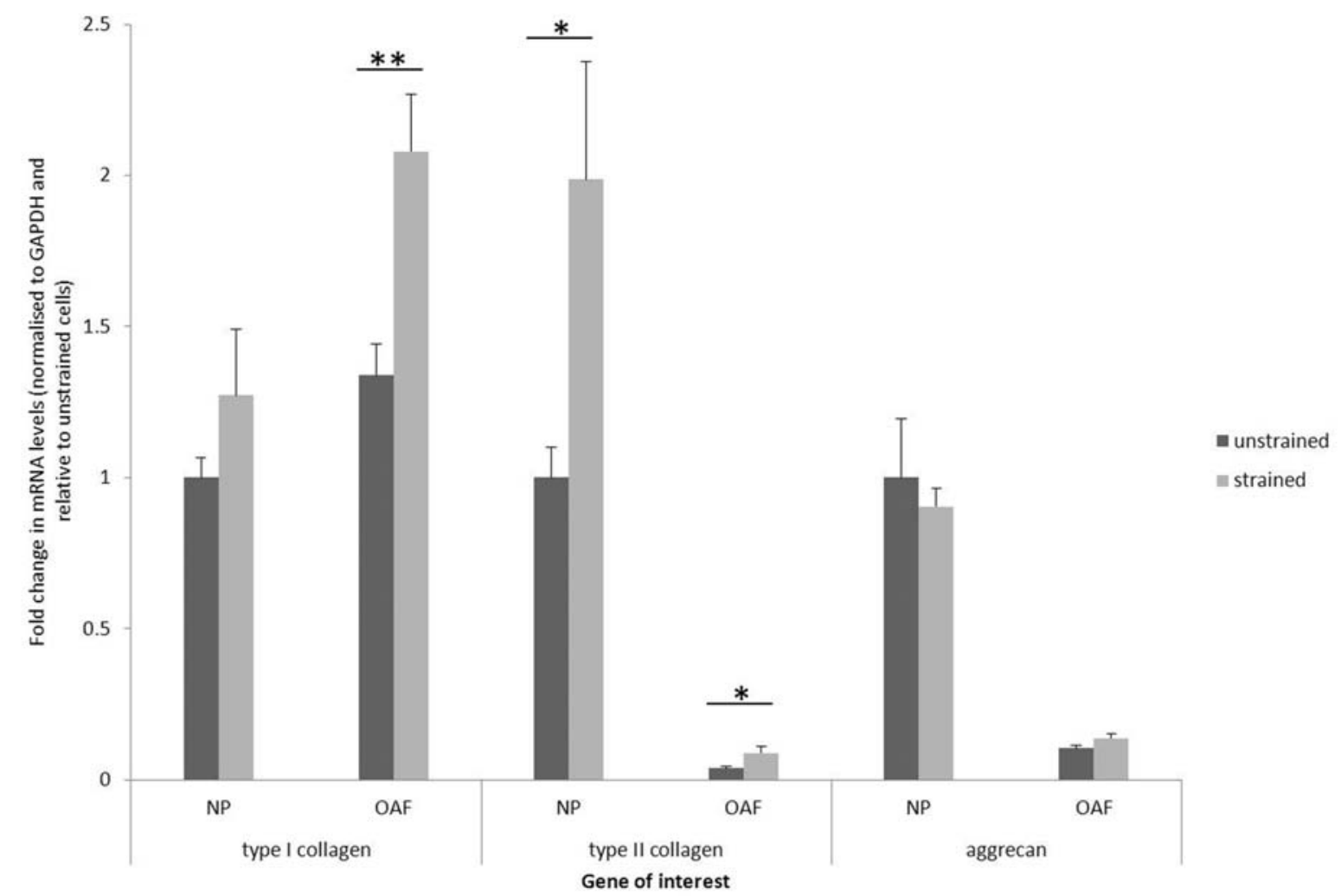

Fig. 5. The effect of tensile strain on transcription of ECM components in NP and OAF cells. Cells were cultured on type I collagen and subjected to strain (10\% elongation, $1 \mathrm{~Hz}, 60 \mathrm{~min})$; unstrained cells were used as controls. Types I and II collagen and aggrecan mRNA levels were determined using real-time PCR. Data are presented as mean fold change \pm S.E.M. after normalisation to the housekeeping gene GAPDH and relative to unstrained "control" cells. $(n=5)$. *: $p \leq 0.05 ; * *: p \leq 0.01$, when compared with the control group.

Strain induced $\beta$-actin protein expression in $O A F$ cells To further investigate whether the alteration in $\beta$-actin gene expression induced a protein change, Western blotting was performed (Fig. 1c). To allow for strain-induced de novo protein synthesis, NP and OAF cells were subjected to 60 min of tensile strain followed by recovery periods of 0,3 , 8 or 24 h at $37^{\circ} \mathrm{C}$. Tensile strain significantly increased $\beta$-actin protein expression in OAF cells after a $3 \mathrm{~h}$ recovery period (approx. 2-fold increase; Two-way ANOVA, $p<$ 0.001 ); this appeared to be a transient response to strain as $\beta$-actin protein levels gradually declined to basal expression by $8 \mathrm{~h}$. Tensile strain did not alter $\beta$-actin protein levels in NP cells at any of the time points analysed (data not shown: $p=0.065$ ).

\section{Strain-induced alterations in transcription of actin- binding proteins in NP and OAF cells}

To elucidate how tensile strain might be modifying F-actin organisation, expression levels of mechano-sensitive actin binding proteins including $\alpha$-actinin, cofilin, filamin A and thymosin $\beta 4$ mRNA levels were investigated using real-time PCR (Fig. 2). There was a small but significant increase in cofilin gene expression in both NP $(p<0.05)$ (Fig. 2a) and OAF cells $(p=0.0011)$ (Fig. 2b) after 60 min of strain. In contrast, there were small, but significant decreases in $\alpha$-actinin $(p=0.0062)$, filamin $\mathrm{A}(p=0.0177)$ and thymosin $\beta 4$ mRNA levels $(p=0.0003)$ in OAF cells in response to tensile strain (Fig. 2b); expression levels of these genes was not affected in strained NP cells (Fig. 2a).

\section{Differential regulation of $\beta$-tubulin in NP and OAF cells exposed to tensile strain}

Strain-induced reorientation of $\beta$-tubulin microtubules in IVD cells

In both NP and OAF cells, the $\beta$-tubulin network appeared as a fibrous meshwork radiating from the cell nucleus towards the cell periphery (Fig. 3a-I \& III). Unlike the OAF cells, an intense peri-nuclear staining of $\beta$-tubulin filaments was also observed in the NP cells (Fig. 3a-I, white arrow). $\beta$-tubulin retained its extensive fibrous meshwork post-strain, however, the filaments aligned more clearly in the direction of strain (Fig. 3a-II \& IV). Peri-nuclear localisation of $\beta$-tubulin was lost in strained NP cells (Fig. 3a-II, hollow white arrow).

Strain induced $\beta$-tubulin transcription in OAF cells $\beta$-tubulin mRNA levels significantly increased in OAF cells subjected to $60 \mathrm{~min}$ of tensile strain (3.4-fold; $p<$ 0.0001), but levels were unaffected in NP cells (Fig. 3b).

Strain-induced synthesis of $\beta$-tubulin protein in OAF cells $\beta$-tubulin protein expression increased in OAF cells, lasting up to $3 \mathrm{~h}$ after application of strain (1.5-fold; Two-way ANOVA, $p=0.0002$ ); levels gradually declined to basal 


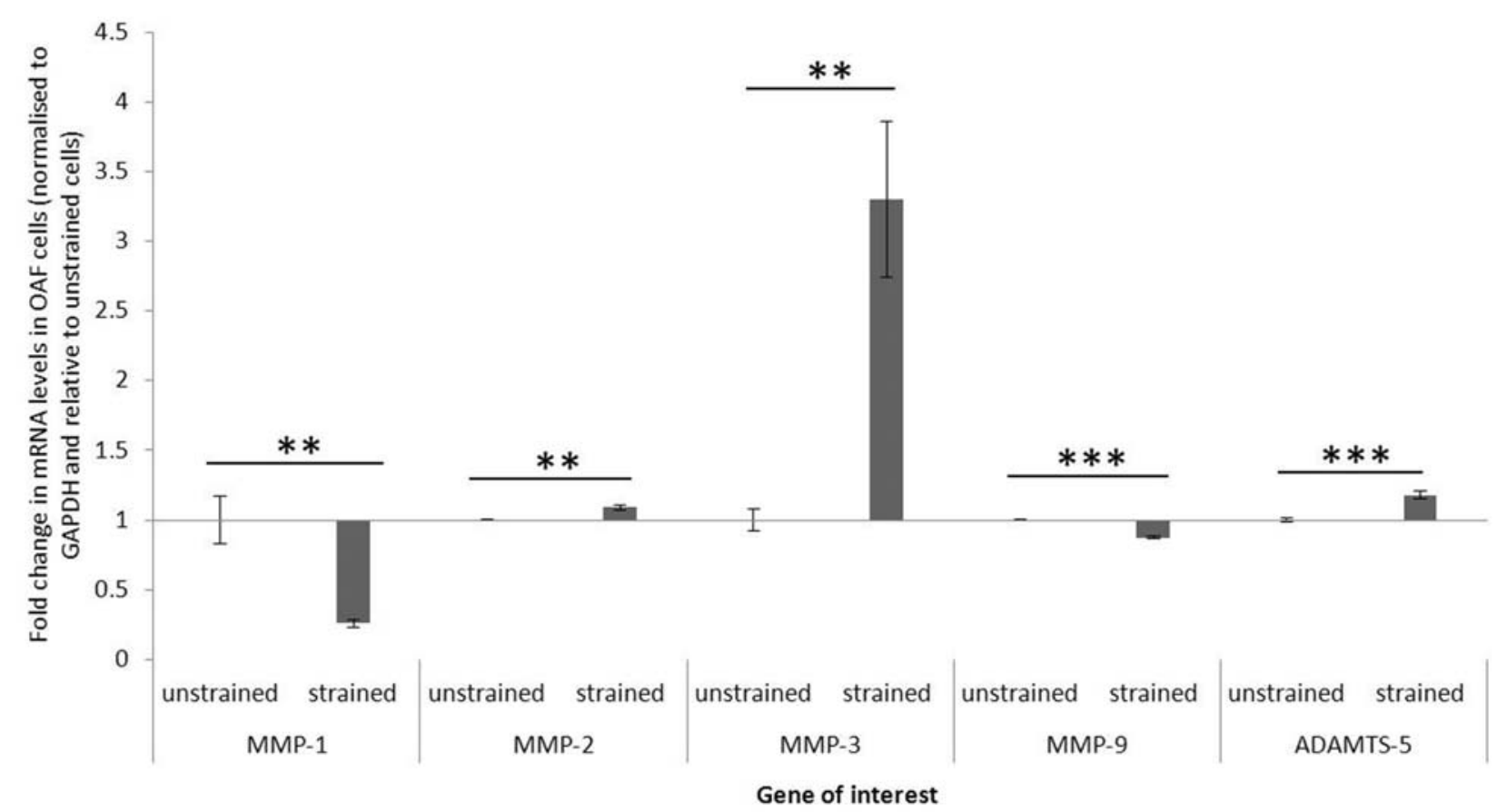

Fig. 6. The effect of tensile strain on transcription of ECM-degrading enzymes in OAF cells. Cells were cultured on type I collagen and subjected to strain (10\% elongation, $1 \mathrm{~Hz}, 60 \mathrm{~min})$; unstrained cells were used as controls. MMPs-1, 2, 3 and 9 and ADAMTS-5 mRNA levels were determined using real-time PCR. Data are presented as mean fold change \pm S.E.M. after normalisation to the housekeeping gene GAPDH and relative to unstrained "control" cells. $(n=5)$. $* * *: p \leq 0.001, * *: p \leq 0.01$, when compared with the control samples.

expression (Fig. 3c). Consistent with the gene expression analysis, $\beta$-tubulin protein synthesis did not alter in strained NP cells (data not shown).

\section{Differential regulation of vimentin intermediate filaments in IVD cells in response to tensile strain} Vimentin filament organisation was unaffected by tensile strain in NP and OAF cells

Vimentin filaments displayed a fibrous network radiating throughout the cytoplasm in NP and OAF cells, with stronger vimentin staining near the nucleus relative to the cell processes (white arrow) (Fig. 4a-I \& III). Strain did not appear to alter vimentin filament organisation, although slightly stronger labelling was observed in the cell processes (white hollow arrow) (Fig. 4a-II \& IV).

Tensile strain decreased vimentin transcript levels in $O A F$ cells

Tensile strain inhibited vimentin transcription in OAF cells (1.9-fold; $p=0.0015)$, but had no effect on expression in NP cells (Fig.4b).

Tensile strain inhibited vimentin protein synthesis in $O A F$ cells

Tensile strain transiently inhibited vimentin protein synthesis in OAF cells (2-fold; Two-way ANOVA, $p=$ 0.0118 ). Following a $3 \mathrm{~h}$ recovery period, vimentin levels had returned to basal amounts (Fig. 4c). Vimentin protein synthesis was unaffected by tensile strain in NP cells at all time points analysed (data not shown).

\section{Strain-induced differential regulation of ECM components in IVD cells}

To further determine how NP and OAF cells respond to tensile strain, transcript levels of key matrix molecules, including types I and II collagen and aggrecan, were investigated using real-time PCR (Fig. 5). Tensile strain induced type I collagen gene expression in OAF cells (1.5-fold; $p=0.0055)$, but did not alter its expression in NP cells $(p=0.2674)$. Type II collagen mRNA levels were significantly elevated in both NP $(1.9$-fold, $p=0.0399)$ and OAF cells $(2.3$-fold, $p=0.0458)$ in response to strain. Aggrecan transcription was not affected by tensile strain in either cell population (Fig. 5).

\section{Differential effects of tensile strain on synthesis of ECM-degrading enzymes and their inhibitors in IVD cells}

Modulation of MMP and ADAMTS mRNA levels in OAF cells subjected to tensile strain

Tensile strain significantly reduced MMP-1 (3.9-fold; $p$ $=0.0028$ ) and MMP-9 mRNA levels (approx. 1.2-fold; $p<0.001$ ) in OAF cells (Fig. 6). In contrast, significant increases in MMP-3 (3.3-fold; $p=0.0036)$, MMP-2 (1.2-fold; $p=0.0017)$ and ADAMTS-5 gene expression (1.25-fold; $p=0.0002)$ was observed after application of strain (Fig. 6). Tensile strain did not affect ECM-degrading enzyme transcript levels in NP cells (data not shown). MMP-13 and ADAMTS-4 transcripts were below the limit of detection in both NP and OAF cells. Although there was a marginal, but significant strain-induced increase in MMP 

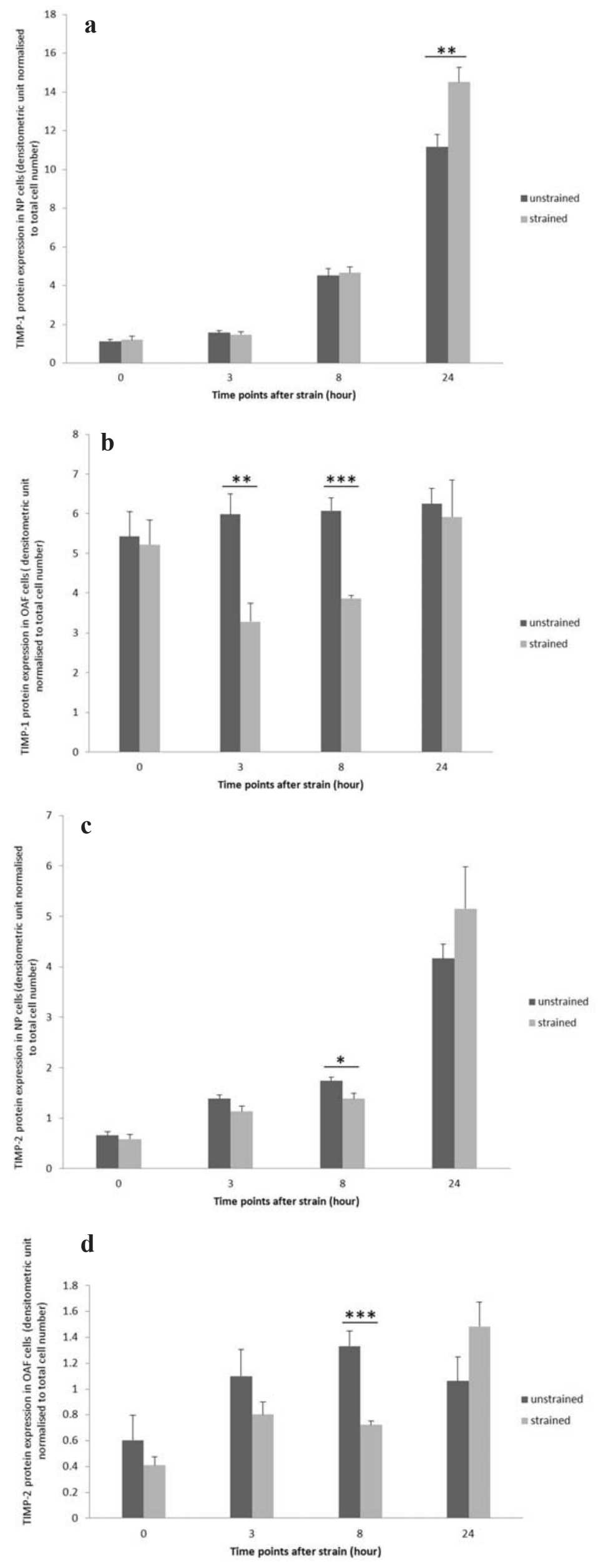

Fig. 7. Expression of TIMPs-1 and -2 in NP and OAF cells in response to tensile strain (a) TIMP-1 in NP, (b) TIMP-1 in OAF, (c) TIMP2 in NP, and (d) TIMP-2 in OAF. Bovine NP and OAF cells cultured on type I collagen were subjected to cyclic tensile strain for $60 \mathrm{~min}$ followed by culture for a further $0,3,8$ or 24 h; TIMPs- 1 and -2 levels in culture media were determined using reverse gelatin zymography (loaded according to equivalent cell number). Data are presented as mean \pm S.E.M. $(n=5)$. $* * *: p \leq 0.001, * *: p \leq 0.01, *: p \leq 0.05$ when compared with the respective control group per time point. 
2 transcription in OAF cells, this was not translated into increased de novo pro MMP-2 protein (data not shown). Active MMP-2 and pro/active MMP-9 enzymes were below the limit of detection.

Tensile strain differentially modulated TIMPs-1 and -2 expression in IVD cells

Tensile strain did not affect TIMPs-1, 2 or 3 transcription in either the NP or OAF cells (data not shown). TIMP-1 protein levels were unaffected by tensile strain (60 min) or following 3 or $8 \mathrm{~h}$ of recovery post-strain in NP cells. However, TIMP-1 was significantly increased in NP cells at $24 \mathrm{~h}$ after the application of tensile strain (1.3-fold; $p$ $=0.0097)$ when compared to levels in unstrained cells (Fig. 7a). In contrast to NP cells, tensile strain transiently reduced TIMP-1 protein synthesis in OAF cells subjected to $60 \mathrm{~min}$ of strain followed by $3(1.8$-fold; $p=0.0040)$ and $8 \mathrm{~h}$ of recovery (1.6-fold; $p=0.0002$, Fig. $7 \mathrm{~b}$ ). Following a $24 \mathrm{~h}$ period of recovery, TIMP-1 expression returned to levels comparable with the unstrained control cells. TIMP-2 levels were initially unaffected by tensile strain in both NP and OAF cells; however following $8 \mathrm{~h}$ of recovery post-strain, TIMP-2 synthesis was transiently decreased in NP (1.3-fold; $p=0.0328$, Fig. 7c) and OAF cells (1.8-fold; $p=0.001$, Fig. $7 \mathrm{~d})$ when compared with equivalent unstrained cells. TIMP-2 expression returned to basal levels, comparable to the unstrained cells, following $24 \mathrm{~h}$ of recovery post-strain in both cell populations (Figs. $7 \mathrm{c}, \mathrm{d})$. TIMP-3 was not detected in either NP or OAF cells.

\section{Discussion}

Mechanical stimulation is an important influencing factor in ECM homeostasis in the IVDs of the spine to maintain functional integrity of the tissue. Previous studies have indicated that the cytoskeleton, which in IVD cells comprises actin microfilaments, tubulin microtubules and vimentin intermediate filaments, can act as a route for propagation of mechanical signals in IVD tissue (Chen et al., 2004; Chiquet et al., 2007). However, there have been few reports characterising the relationship between mechanical stimulation and the cytoskeleton in IVD cell mechanotransduction.

Intervertebral discs comprise at least two distinct cell populations: NP cells which appear "chondrocyte"-like and OAF cells which are "fibroblast"-like in morphology. This reflects the distinct matrix organisation of the disc regions (Urban and Roberts, 2003). In this study, both NP and OAF cells were cultured as a monolayer on type I collagen, which significantly changes the cellular morphology when compared with that in vivo. To assess the cell phenotypes, mRNA levels of types I and II collagen as well as aggrecan were investigated using real-time PCR (data not shown). Type II collagen and aggrecan mRNA levels were significantly higher in NP cells compared to OAF cells where more type I collagen mRNA was expressed. These results illustrate that both NP and OAF cells maintained their basic cell phenotypes; subtle alterations in NP cell morphology was observed during the monolayer culture where cells became slightly flattened but still abundantly expressed type II collagen (phenotypic marker).

$10 \%$ elongation was applied in this series of experiments as it has previously been shown that the OAF region of the IVD is subjected to a strain of between 1 and $13 \%$ (Broberg, 1983; Klein et al., 1983; Ebara et al., 1996; Rannou et al., 2003; Gilbert et al., 2010). Clearly, NP cells are not normally exposed to tensile force, predominantly experiencing compressive and/or hydrostatic pressure in vivo. Hence, this study has compared the response of the IVD cell populations to a mechanical stimulus, namely cyclic tensile strain which is considered physiological to OAF cells and non-physiological to NP cells. A frequency of $1 \mathrm{~Hz}(0.5 \mathrm{~s}$ elongation, followed by $0.5 \mathrm{~s}$ relaxation $)$ was applied which is equivalent to the physiological frequency generated by walking during daily life in vivo (Skaggs et al., 1994).

Our data clearly demonstrate that the cytoskeletal networks were sensitive to tensile strain and interestingly greater effects were observed in the OAF cells, as might be expected because OAF cells endure tensile strain in vivo. F-actin distribution in the monolayer cultured NP and OAF cells was comparable to their organisation in situ (Li et al. 2008), although a more filamentous network was apparent which may result from the monolayer culture system used. However, tensile strain remodelled the F-actin cytoskeleton in both OAF and NP cells. A greater number of actin stress fibres were visible in cells, comparable to a study performed on chondrocytes (Iscru et al., 2008); this suggests that tensile strain can remodel F-actin organisation in both NP and OAF cells and may act as a conduit for transducing mechanical signals. Strain-induced F-actin remodelling was further investigated to determine whether the observed effects were purely organisational or due to alterations in transcription and translation. Tensile strain induced $\beta$-actin transcription in both NP and OAF cells. However, this was only evident at the protein level in OAF cells as assessed by Western blotting. To determine whether the observed F-actin remodelling may have been modulated by the differential regulation of accessory proteins, as has previously been reported in chondrocytes (Blain et al., 2002; Blain et al., 2003; Campbell et al., 2007), mRNA expression levels of the actin-binding proteins was analysed. Tensile strain increased the transcription of cofilin in both NP and OAF cells, whilst decreasing expression of $\alpha$-actinin, filamin $A$ and thymosin $\beta_{4}$ in OAF cells. Although differences in actin-binding protein transcript levels are relatively modest, it demonstrates that these genes are mechano-sensitive, and that with time, may induce a significant biological effect as a consequence. Cofilin severs actin filaments to provide free barbed ends for actin polymerisation and nucleation (Ichetovkin et al., 2002), thymosin $\beta_{4}$ sequesters the ATP-bound G-actin to prevent its availability for polymerisation (Weber et al., 1992), whilst filamin A promotes actin filament assembly (Koteliansky et al., 1981). Differential transcriptional regulation of these actin-binding proteins suggests that tensile strain enhances the rate of actin turnover promoting increased production of stress fibres to adapt to the altered mechanical environment. 
In complete contrast to the observed remodelling of F-actin, the $\beta$-tubulin architecture in NP and OAF cells was unresponsive to tensile strain. However, strain induced $\beta$-tubulin gene and protein expression in OAF cells. Microtubules are essential for intracellular protein transport (Pellegrini and Budman, 2005), synthesis and secretion of collagen (Blain, 2009) and are intimately associated with the ability of the cell to withstand mechanical deformation and resist strain-induced volumetric changes (Ofek et al., 2009). Microtubule disruption in heart myocytes (Samuel et al., 1986; Takahashi et al., 1998) and articular cartilage (Jortikka et al., 2000) abrogated mechanically-induced ECM remodelling. The observed increase in $\beta$-tubulin mRNA and protein synthesis in OAF cells may reflect a response to meet cellular demands i.e., ECM turnover, as collagen types I and II transcription were induced by strain. Equally, increased $\beta$-tubulin synthesis may be necessary to promote and maintain an assembled microtubule network to protect the cell from mechanical damage, as tensile strain has previously been shown to increase microtubule assembly (Putnam et al., 2001). Although the precise mechanism of microtubule involvement in mechanosignalling is unclear, they are essential for transmitting stresses to activate other cytoplasmic proteins within the signalling cascade(s) (Putnam et al., 2003; Na and Wang, 2008).

In our study, vimentin organisation did not alter appreciably in response to tensile strain in OAF or NP cells, although there was evidence of increased vimentin staining in cell processes. Strain inhibited vimentin transcription in OAF cells but this alteration was only transiently reflected at the protein level, suggesting that vimentin may not be mechano-sensitive in bovine IVD cells, as has previously been alluded to in smooth muscle cells (Albinsson et al., 2004). Organisation of the vimentin architecture was assessed after $60 \mathrm{~min}$ of tensile strain; vimentin filament turnover is highly dynamic (Blain, 2009) and it is feasible that strain-induced vimentin remodelling may have been an earlier event of which the downstream consequences of its rearrangement have been measured in this study. The main functions of vimentin filaments are to provide the cell with its shape and its elastic properties in resisting mechanical forces (Galou et al., 1997; Pekny and Lane, 2007). It is slightly surprising that tensile strain does not more obviously remodel the vimentin network considering the extent of its interaction with F-actin and $\beta$-tubulin, which are mechano-responsive although vimentin remodelling may have been an early event that was not captured by our timeframe of analysis. In vimentin -/- mice, lack of this cytoskeletal protein significantly inhibited the response of mesenteric resistance arteries to shear stress, but not tensile force, suggesting vimentin may only be sensitive to particular types of mechanical stimuli (Henrion et al., 1997).

In situ, the OAF is characterised by type I collagen and the NP by aggrecan and type II collagen expression. It is widely believed that the distribution of the ECM components reflects the distinct mechanical stresses which the tissue has to resist: the presence of type I collagen in the OAF endures tensile force in vivo, and compressive loads are resisted by the abundance of proteoglycan and type II collagen in the NP. In this study, type I collagen transcription increased in OAF cells but not in NP cells in response to strain, likely reflecting the cells' requirement to lay down a matrix to withstand tensional forces. Interestingly, application of this loading regime to OAF cells derived from skeletally mature calf IVDs (18 monthold) did not alter type I collagen transcription (manuscript in preparation), suggesting an altered mechano-sensitivity in mature IVD cells.

ECM homeostasis is regulated by mechanical stimulation, such that a balance between matrix synthesis and degradation is maintained under physiological conditions. Mechano-regulation of the MMPs, enzymes that degrade ECM components, has been investigated in many cell types (Blain et al., 2001; Patwari et al., 2003; Lin et al., 2004). MMP-3, a highly expressed MMP in IVD, was significantly elevated in response to tensile strain. MMP-3 has both anabolic and catabolic properties; it is important in cartilage formation (Pelttari et al., 2008) but can also activate other MMPs such as MMP-1 (Murphy et al., 1987), ultimately playing an important role in disc degeneration (Haro et al., 2000). In our study, tensile strain inhibited MMPs- 1 and -9 mRNA expression in OAF cells, which coincided with a transient decline of the endogenous inhibitors - TIMP-1 and TIMP-2. The strain-induced reduction in MMP-1 expression is consistent with previous observations in which strain (6 $\%$ elongation, $0.05 \mathrm{~Hz}$ ) abrogated IL-1 induced MMP-1 expression in fibrochondrocytes (Agarwal et al., 2001). Physiological levels of cyclic strain were suggested to confer protection by exerting an "anti-catabolic" effect (Long et al., 2001). Load-induced suppression of MMPs-1 and -9 expression observed in our study suggests that the physiological loading regime used $(10 \%, 1 \mathrm{~Hz}, 60 \mathrm{~min})$ was anabolic stimulating ECM synthesis in OAF cells. Inhibition of MMP transcription was recently reported in strained normal human annulus fibrosus cells (10\%, $1 \mathrm{~Hz}$ ) (Gilbert et al., 2010). Gilbert et al. demonstrated that altering the frequency $(0.33 \mathrm{~Hz})$ invoked a catabolic response indicating the importance of the loading regime in the cells' responses.

Interestingly, most of our observed responses to tensile strain were only apparent in OAF cells, suggesting a close relationship between cell phenotype and the mechanical environment it is inherently exposed to i.e. tension. Clearly, the cytoskeletal elements are important in perceiving a mechanical stimulus, undergoing structural reorganisation to exert a biological effect. Extensive cytoskeletal element remodelling was only observed in OAF cells in response to tensile strain; concomitant with remodelling of the cytoskeleton architecture was the differential transcriptional regulation of key ECM molecules. It is likely that the unresponsiveness of the NP cells to remodel their cytoskeleton within the time scale of these experiments prevented strain-induced transcriptional effects. It is widely regarded that cytoskeletal protein remodelling can modulate cell signalling pathways upstream of gene transcription in other cell types i.e. chondrocytes. Further studies are needed to elucidate the precise signalling mechanisms of the specific cytoskeletal elements in IVD mechanotransduction. 


\section{Conclusion}

Our results presented here, show for the first time that tensile strain induces divergent intracellular responses between OAF and NP cells in the organisation and expression of cytoskeletal elements and on markers of ECM metabolism. The increased response of OAF cells to tensile strain and the largely unresponsive NP cells likely reflects their distinct mechanical environments in situ.

\section{Acknowledgements}

We acknowledge funding from the EPSRC (Engineering and Physical Sciences Research Council) (Dorothy Hodgkin Postgraduate Award to S.L.) and Arthritis Research UK (grant no. 18221 to E.J.B.).E.J.B is an academic fellow funded by Arthritis Research UK within the Biomechanics and Bioengineering Centre. The E7 monoclonal antibody developed by Michael Klymkowsky was obtained from the Developmental Studies Hybridoma Bank developed under the auspices of the NICHD and maintained by the University of Iowa, Department of Biological Sciences, Iowa City, IA 52242.

\section{References}

Agarwal S, Long P, Gassner R, Piesco NP, Buckley MJ (2001) Cyclic tensile strain suppresses catabolic effects of interleukin-1beta in fibrochondrocytes from the temporomandibular joint. Arthritis Rheum 44: 608-617.

Albinsson S, Nordstrom I, Hellstrand P (2004) Stretch of the vascular wall induces smooth muscle differentiation by promoting actin polymerization. J Biol Chem 279: 34849-34855.

Benallaoua M, Richette P, Francois M, Tsagris L, Revel M, Corvol M, Poiraudeau S, Savouret JF, Rannou F (2006) Modulation of proteoglycan production by cyclic tensile stretch in intervertebral disc cells through a posttranslational mechanism. Biorheology 43: 303-310.

Blain EJ (2009) Involvement of the cytoskeletal elements in articular cartilage homeostasis and pathology. Int J Exp Pathol 90: 1-15.

Blain EJ, Gilbert SJ, Hayes AJ, Duance VC (2006) Disassembly of the vimentin cytoskeleton disrupts articular cartilage chondrocyte homeostasis. Matrix Biol 25: 398 408.

Blain EJ, Gilbert SJ, Wardale RJ, Capper SJ, Mason DJ, Duance VC (2001) Up-regulation of matrix metalloproteinase expression and activation following cyclical compressive loading of articular cartilage in vitro. Arch Biochem Biophys 396: 49-55.

Blain EJ, Mason DJ, Duance VC (2002) The effect of thymosin beta4 on articular cartilage chondrocyte matrix metalloproteinase expression. Biochem Soc Trans 30: 879-882.

Blain EJ, Mason DJ, Duance VC (2003) The effect of cyclical compressive loading on gene expression in articular cartilage. Biorheology 40: 111-117.
Broberg KB (1983) On the mechanical behaviour of intervertebral discs. Spine 8: 151-165.

Campbell JJ, Blain EJ, Chowdhury TT, Knight MM (2007) Loading alters actin dynamics and up-regulates cofilin gene expression in chondrocytes. Biochem Biophys Res Commun 361: 329-334.

Chen J, Yan W, Setton LA (2004) Static compression induces zonal-specific changes in gene expression for extracellular matrix and cytoskeletal proteins in intervertebral disc cells in vitro. Matrix Biol 22: 573-583.

Chiquet M, Tunc-Civelek V, Sarasa-Renedo A (2007) Gene regulation by mechanotransduction in fibroblasts. Appl Physiol Nutr Metab 32: 967-973.

Ebara S, Iatridis JC, Setton LA, Foster RJ, Mow VC, Weidenbaum M (1996) Tensile properties of nondegenerate human lumbar anulus fibrosus. Spine 21: 452-461.

Galou M, Gao J, Humbert J, Mericskay M, Li Z, Paulin D, Vicart P (1997) The importance of intermediate filaments in the adaptation of tissues to mechanical stress: evidence from gene knockout studies. Biol Cell 89: 85-97.

Gilbert HT, Hoyland JA, Millward-Sadler SJ (2010) The response of human annulus fibrosus cells to cyclic tensile strain is frequency-dependent and altered with disc degeneration. Arthritis Rheum 62: 3385-3394.

Haro H, Crawford HC, Fingleton B, MacDougall JR, Shinomiya K, Spengler DM, Matrisian LM (2000) Matrix metalloproteinase-3-dependent generation of a macrophage chemoattractant in a model of herniated disc resorption. $\mathrm{J}$ Clin Invest 105: 133-141.

Hayes AJ, Benjamin M, Ralphs JR (2001) Extracellular matrix in development of the intervertebral disc. Matrix Biol 20: 107-121.

Henrion D, Terzi F, Matrougui K, Duriez M, Boulanger CM, Colucci-Guyon E, Babinet C, Briand P, Friedlander G, Poitevin P, Lévy BI (1997) Impaired flow-induced dilation in mesenteric resistance arteries from mice lacking vimentin. J Clin Invest 100: 2909-2914.

Ichetovkin I, Grant W, Condeelis J (2002) Cofilin produces newly polymerized actin filaments that are preferred for dendritic nucleation by the Arp2/3 complex. Curr Biol 12: 79-84.

Iscru DF, Anghelina M, Agarwal S, Agarwal G (2008) Changes in surface topologies of chondrocytes subjected to mechanical forces: an AFM analysis. J Struct Biol 162: 397-403.

Jortikka MO, Parkkinen JJ, Inkinen RI, Karner J, Jarvelainen HT, Nelimarkka LO, Tammi MI, Lammi MJ (2000) The role of microtubules in the regulation of proteoglycan synthesis in chondrocytes under hydrostatic pressure. Arch Biochem Biophys 374: 172-180.

Kaverina I, Krylyshkina O, Beningo K, Anderson K, Wang YL, Small JV (2002) Tensile stress stimulates microtubule outgrowth in living cells. J Cell Sci 115: 2283-2291.

Klein JA, Hickey DS, Hukins DW (1983) Radial bulging of the annulus fibrosus during compression of the intervertebral disc. J Biomech 16: 211-217.

Koteliansky VE, Shirinsky VP, Gneushev GN, Smirnov VN (1981) Filamin, a high relative molecular mass actinbinding protein from smooth muscles, promotes actin polymerization. FEBS Lett 136: 98-100. 
Li S, Duance VC, Blain EJ (2008) Zonal variations in cytoskeletal element organization, mRNA and protein expression in the intervertebral disc. J Anat 213: 725-732.

Lin PM, Chen CT, Torzilli PA (2004) Increased stromelysin-1 (MMP-3), proteoglycan degradation (3B3and 7D4) and collagen damage in cyclically load-injured articular cartilage. Osteoarthritis Cartilage 12: 485-496.

Matsumoto T, Kawakami M, Kuribayashi K, Takenaka T, Tamaki T (1999) Cyclic mechanical stretch stress increases the growth rate and collagen synthesis of nucleus pulposus cells in vitro. Spine 24: 315-319.

Mirza SK, White AA 3rd (1995) Anatomy of intervertebral disc and pathophysiology of herniated disc disease. J Clin Laser Med Surg 13: 131-142.

Murphy G, Cockett MI, Stephens PE, Smith BJ, Docherty AJ (1987) Stromelysin is an activator of procollagenase. A study with natural and recombinant enzymes. Biochem J 248: 265-268.

Na S, Wang N (2008) Application of fluorescence resonance energy transfer and magnetic twisting cytometry to quantify mechanochemical signaling activities in a living cell. Sci Signal 1: pl1.

Ofek G, Wiltz DC, Athanasiou KA (2009) Contribution of the cytoskeleton to the compressive properties and recovery behavior of single cells. Biophys J 97: 1873-1882.

Patwari P, Cook MN, DiMicco MA, Blake SM, James IE, Kumar S, Cole AA, Lark MW, Grodzinsky AJ (2003) Proteoglycan degradation after injurious compression of bovine and human articular cartilage in vitro: interaction with exogenous cytokines. Arthritis Rheum 48: 1292-1301.

Pekny M, Lane EB (2007) Intermediate filaments and stress. Exp Cell Res 313: 2244-2254.

Pellegrini F, Budman DR (2005) Review: tubulin function, action of antitubulin drugs, and new drug development. Cancer Invest 23: 264-273.

Pelttari K, Lorenz H, Boeuf S, Templin MF, Bischel O, Goetzke K, Hsu HY, Steck E, Richter W (2008) Secretion of matrix metalloproteinase 3 by expanded articular chondrocytes as a predictor of ectopic cartilage formation capacity in vivo. Arthritis Rheum 58: 467-474.

Putnam AJ, Cunningham JJ, Pillemer BB, Mooney DJ (2003) External mechanical strain regulates membrane targeting of Rho GTPases by controlling microtubule assembly. Am J Physiol Cell Physiol 284: C627-639.

Putnam AJ, Schultz K, Mooney DJ (2001) Control of microtubule assembly by extracellular matrix and externally applied strain. Am J Physiol Cell Physiol 280: C556-564.

Rannou F, Richette P, Benallaoua M, Francois M, Genries V, Korwin-Zmijowska C, Revel M, Corvol M, Poiraudeau S (2003) Cyclic tensile stretch modulates proteoglycan production by intervertebral disc annulus fibrosus cells through production of nitrite oxide. J Cell Biochem 90: 148-157.

Samuel JL, Marotte F, Delcayre C, Rappaport L (1986) Microtubule reorganization is related to rate of heart myocyte hypertrophy in rat. Am J Physiol 251: H11181125.

Setton LA, Chen J (2004) Cell mechanics and mechanobiology in the intervertebral disc. Spine 29: 2710-2723.
Skaggs DL, Weidenbaum M, Iatridis JC, Ratcliffe A, Mow VC (1994) Regional variation in tensile properties and biochemical composition of the human lumbar anulus fibrosus. Spine 19: 1310-1319.

Takahashi M, Tsutsui H, Tagawa H, Igarashi-Saito K, Imanaka-Yoshida K, Takeshita A (1998) Microtubules are involved in early hypertrophic responses of myocardium during pressure overload. Am J Physiol 275: H341-348.

Urban JP, Roberts S (2003) Degeneration of the intervertebral disc. Arthritis Res Ther 5: 120-130.

Weber A, Nachmias VT, Pennise CR, Pring M, Safer D (1992) Interaction of thymosin beta 4 with muscle and platelet actin: implications for actin sequestration in resting platelets. Biochemistry 31: 6179-6185.

Yu SJ, Qiu GX, Burton Y, Sandra R, Cari W, Albert Y (2005) [Expression of integrin alpha5 and actin in the cells of intervertebral disc under cyclic hydrostatic pressure in vitro]. Zhonghua Wai Ke Za Zhi 43: 1605-1608.

\section{Discussion with Reviewers}

Reviewer I: The experimental model chosen here for cell culture and mechanical loading (a collagen type I coated monolayer substrate) corresponds much better to the physiological in situ environment of AF cells than for NP cells. How could a possible dedifferentiation of NP cells on this substrate influence the observed results and why do the authors think that their results reflect the respective mechanical environment in situ?

Authors: Yes, the experimental model chosen best reflects the mechanical environment of OAF cells in vivo. We agree that NP cells do not normally experience tensile strain in situ and so this represents a non-physiological mechanical stimulus. However, we felt that comparing how two unique cell populations respond to a specific mechanical stimulus would inform on possible divergent mechanisms of cell signalling. We do not believe that the NP cells used in these experiments underwent dedifferentiation as they were seeded at high density and cultured in ITS supplement which maintains the cell phenotype, as evidenced by continued type II collagen expression by the NP cells. In addition, if the NP cells had differentiated into a more "fibroblast-like" phenotype, we believe that the response of the NP cells to tensile strain would have been comparable to the effects on the OAF cells. There are clear differences in their responses to the mechanical stimulus; these biological effects represent responses of OAF cells exposed to a physiological and NP cells exposed to a non-physiological mechanical stimulus in vitro.

Reviewer I: The experimental system used in this study (deformable 2D membrane) provides a relatively uniform, defined mechanical stimulus and allows for easy biological assessment of cells (e.g., collecting lysates). The biggest drawback, however, is that it takes cells out of the context of their native ECM environment. What future experiments can be performed to better assess cell responses within the context of the tissue?

Authors: We agree that the model system we have used allows for easy biological analysis and clearly not representative of the native environment due to the 
removal of the surrounding matrix. However, due to its ease of manipulation we have been able to dissect apart the differential involvement of the cytoskeletal elements in propagating mechanical signals in the NP and OAF cells. Now that we have an understanding of which cytoskeletal networks are responsive to tensile strain, future experiments could be performed in IVD explants. However, few studies have been performed on explants in situ as it comes with its own challenges; IVD tissue would have to be subjected to compressive load to initiate tensile strain in the OAF - accurately measuring these strains would not be simple. An alternative strategy which has previously been reported by the laboratory of Iatridis (University of Vermont) amongst others is the in vivo rat tail model, whereby compressive loads are applied to the tail discs in situ and fine dissection of the NP from the OAF is conducted to allow for analysis. This model also allows for the manipulation of the tissue to endure static compression, bending and torsion movement associated with the spine.

Reviewer II: Is it possible to design this type of experiment with cells in a more appropriate ECM context (i.e., 3D, within their native matrix)?

Authors: Yes, in parallel experiments we seeded NP or OAF cells into $3 \%(\mathrm{v} / \mathrm{v})$ agarose constructs as previously described for chondrocytes (Knight et al., 2006). Cells were stabilised for $24 \mathrm{~h}$, sufficient time to start depositing an immediate pericellular matrix, prior to the application of a $10 \%$ compressive strain. The response of NP and OAF cells to this mechanical stimulus was then assessed. However, using the Flexcell FX-3000 system as we have in this current study, cells have to be seeded as a monolayer on specific culture plates as the system relies on the deformation of the plate membrane in order to allow a uniform biaxial displacement of the cells. The cells seeded in agarose are unconfined, therefore application of the compressive strain results in tension at the construct periphery where "bulging" occurs. It would be difficult to perform these experiments on cells in their native matrix environment in situ, although several studies have previously been conducted by applying tensile strain to rodent tail discs in vivo to assess IVD mechanotransduction.

Reviewer II: The monolayer culture system used in this study is certainly better suitable to support the more fibroblast-like phenotype of AF cells than the NP cell phenotype. How do the authors think would a coating of the substrate with proteins that better simulate the ECM environment of both cell types in vivo (type I collagen for AF cells/ aggrecan and type II collagen for NP cells) influence the organisation and expression of cytoskeletal elements?

Authors: In situ the OAF cells are "fibroblast-like" in morphology and are surrounded by a matrix rich in type I collagen, whereas the NP cells are classically "chondrocytelike" and embedded in a matrix comprised of type II collagen and aggrecan. Our previous investigation of the organisation of the cytoskeleton in NP and OAF cells in situ (Li et al., 2008, text reference) demonstrated that there are inherent differences in the spatial localisation of the three cytoskeletal networks. These in situ characteristics were reflected in the localisation of the cytoskeletal networks observed in the isolated OAF cells embedded on type I collagen and NP cells embedded in agarose synthesising a native pericellular matrix (submitted manuscript). Clearly, the ECM environment will contribute to the mechanosignalling mechanisms, however, we believe that the organisation and expression of the cytoskeletal elements more likely reflects the unique morphology of the cells i.e. elongated versus spherical and be primarily influenced by the type of mechanical stimulation applied.

\section{Additional Reference}

Knight MM, Toyoda T, Lee DA, Bader DL (2006) Mechanical compression and hydrostatic pressure induce reversible changes in actin cytoskeletal organisation in chondrocytes in agarose. J Biomech 39: 1547-1551. 